\title{
Aumentan las herramientas de comunicación basadas en la evidencia pero son poco utilizadas
}

Trevena LJ y Col. J.Eval Clin Pract. 2006;12(1):13-23

\section{Objetivo}

Determinar la efectividad de las herramientas de comunicación basadas en la evidencia (HCBE) para incrementar la comprensión, formatos efectivos para representar la información probabilística y estrategias efectivas de identificación de las prefe-rencias de los pacientes acerca de la evidencia.

\section{Fuente y selección de datos}

Se buscaron Revisiones Sistemáticas (RS) y Ensayos Clínicos Aleatorizados (ECA) en lengua inglesa en Cochrane Library, Medline, Psychinfo, Embase and Cancerlit a Junio 2004. No se incluyó literatura gris*. Los estudios eran excluidos si no abordaban las preguntas, si se centraban en cambios de comportamiento sin intentar incrementar la comprensión o en consejos como intervención terapéutica, o fueran específicos a la comunicación independientemente de su participación en el ECA.

Se evaluó la calidad de las $\mathrm{RS}^{1}$ y dos revisores independientes, los $\mathrm{ECA}^{2,3}$. Se evitaron duplicaciones de estudios y se excluyeron ECA con alto riesgo de sesgo (como no reportar el método de aleatorización).

\section{Extracción de datos}

Se evaluaron las siguientes intervenciones: ayudas para la toma de decisión, folletos, videos, sitios web, programas de computación personalizados, consejo verbal o estructurado; reportes de riesgo absoluto y relativo, gráficos (Histogramas, tortas, mapas, gráficos lineales, 100 caras) imágenes, ilustraciones, diagramas y palabras del texto; ayudas para la toma de decisión, herramientas de análisis de decisión, toque de pantalla y cuestionarios.

Los resultados evaluados fueron entendimiento, conocimiento y comprensión para los primeros tres objetivos; y satisfacción con la decisión, adherencia a la decisión, ansiedad, conflicto de decisión, involucramiento con el proceso de toma de decisión para el último.

\section{Resultados principales}

Se encontraron diez revisiones sistemáticas (RS) de ECA y 30 ECA adicionales que abordaron las preguntas. Las RS no pudieron combinar datos por heterogeneidad* o por falta de datos.

Las HCBA aumentan la comprensión de los pacientes en la mayoría de los formatos (verbal, escrito, video, provisto por el personal de salud, basado en computadoras) pero más probablemente si eran estructuradas, personalizadas y/o interactivas (computadora, toque de pantalla, preguntas).

La información probabilística se representa mejor como proporciones de eventos $(\%, \%)$ en grupos determinados de personas, probabilidades o medidas de efecto como la reducción de riesgo relativo o absoluto salvo que se también presenten los riesgos basales.

Las ilustraciones como gráficos (especialmente de barras verticales con estimadores numéricos) o dibujos (particularmente en bajos niveles educativos) parecen ayudar a la comprensión.

Los ejercicios de clarificación de valores pueden ser mejores que las técnicas estándar (métodos de la apuesta y de la negociación con el tiempo*) para reconocer las preferencias en la toma de decisión individual.

La búsqueda de eficaces HCBE para el caso de rastreo de cáncer de próstata resaltó los desafíos para médicos y pacientes en acceder a dichas HCBE.

\section{Conclusiones}

Existe un creciente cuerpo de la evidencia que avala el diseño de efectivas HCBE pero es variable el acceso en la práctica de dichas herramientas.

Fuente de financiamiento: no referida.

\section{Comentario}

Existen imperativos morales, éticos y legales que exigen que los pacientes reciban información de alta calidad ${ }^{1,3}$. Sin embargo debe reconocerse que las decisiones de los pacientes basadas en la evidencia requieren un complejo proceso de integración de la información con resultados clínicos, factores contextuales y preferencias de los pacientes ${ }^{4}$. Hay modelos de decisión participativa e instrumentos (DISCIERN ${ }^{5}$ ) útiles para eva-luar la calidad de información del paciente, sin embargo la presente RS abordó gran parte de la información relevante sobre la eficacia de las HCBE.

En esta revisión de revisiones ("overview") no fue posible combinar los resultados y por ende no se evaluó la heterogeneidad ni el sesgo de publicación (ambas probables a juzgar por el análisis de las RS y ECA incluidos). La consistencia de la dirección de los efectos en una amplia variedad de escenarios aumenta la generalizabilidad y la validez de sus resultados. Aunque la estrategia de búsqueda fue amplia la restricción a estudios en inglés limita la extrapolación hacia culturas muy distintas que usan otros idiomas.

\section{Conclusión del comentador}

Hay evidencia buena de que las HCBE aumentan la comprensión del paciente y el conocimiento en la toma de decisiones en salud. Sin embargo aun se necesitan más investigaciones, especialmente multiculturales, para determinar los métodos más eficaces de comunicación considerando las preferencias de los pacientes. Asimismo se necesita mejorar el acceso a los médicos y usuarios a las mejores HCBE. Si ésto no fuera posible la información estructurada, verbal o escrita, es también una herramienta eficaz.

Agustín Ciapponi [ Unidad de Medicina Familiar y Preventiva. Hospital Italiano de Buenos Aires. ]

Ciapponi A. Aumentan las herramientas de comunicación basadas en la evidencia pero son poco usadas. Evid. actual. páct. ambul. 9(2);47. Mar-Abr 2006. Comentado de: Trevena LJ, Davey HM, Barratt A, Butow P, Caldwell P. A systematic review on communicating with patients about evidence. J Eval Clin Pract. 2006;12(1):13-23. PMID: 16422776

\section{Referencias}

1. Evidence-Based Medicine Working Group (2002) Users' Guides to the Medical Literature. A Manual for Evidence-Based Clinical Practice. AMA Press, Chicago, IL.

2. Glasziou P., Irwig L., Bain C. \& Colditz G. (2001) Systematic Reviews in Health Care. A Practical Guide. University Press, Cambridge, UK. Cochrane Collaboration (2003) Cochrane Reviewers'Handbook 4.1.6.

3. General Medical Council (1998) Seeking patients' consent: the ethical considerations, http://www.gmc-uk.org/standards/consent.htm (accessed 28 February 2005).

4. Haynes R., Devereaux P. \& Guyatt G. (2002) Clinical expertise in the era of evidence-based medicine and patient choice. Evidence-Based Medicine 7, 36-8. 5. Charnock D., Sheppard S., Needham G. \& Gann R. (1999) DISCERN: an instrument for judging the quality of written consumer health information on treatment choices. Journal of Epidemiology and Community Health 53, 105-11. 